\title{
Ações de pesquisa e extensão no projeto laboratório de tecnologias intelectuais ${ }^{1}$
}

\author{
Research and extension actions in the intellectual \\ technology laboratory project
}

Isa Maria FREIRE 2,3

Edvaldo Carvalho ALVES2,3

Julio Afonso Sá de PINHO NETO2,3

Marckson Ferreira de SOUSA ${ }^{4}$

\section{Resumo}

Este trabalho apresenta os primeiros resultados do Projeto Laboratório de Tecnologias Intelectuais, em desenvolvimento mediante parceria entre o Departamento de Ciência da Informação e o Programa de Pós-Graduação em Ciência da Informação da Universidade Federal da Paraíba. O Projeto visa promover ações para propiciar o acesso à informação e à formação de competências em informação, através da Internet, bem como a troca produtiva de conhecimentos e experiências entre pesquisadores, bolsistas e usuários. Propõe ações em nível de pesquisa (o projeto em si), ensino (educação a distância) e extensão (cursos e tutoriais), abordando as tecnologias intelectuais e suas aplicações em um ambiente de compartilhamento de conhecimentos. Este artigo relata resultados já alcançados desde o início do Projeto, em 2009, especialmente a experiência com a Oficina de Criatividade Científica, curso de extensão presencial com atividades on-line, que proporciona aos participantes a oportunidade de conhecer e trabalhar as abordagens e metodologias do campo da Ciência da Informação.

Palavras-chave: Ciência da Informação. Competências em informação. Educação continuada. Regime de informação. Tecnologias intelectuais.

\begin{abstract}
This paper presents the initial results of the Intellectual Technologies Laboratory Project, developed through a partnership between the Information Sciences Department and Postgraduate Program in Information Science at the Universidade Federal da Paraíba. The Intellectual Technologies Laboratory Project promotes actions to provide access to information and skills training in information via the Internet, and a productive exchange of knowledge and experiences among researchers, fellows and users. It proposes actions at the research level (the project itself), open and distance learning and extension (courses and tutorials), addressing intellectual technologies and their application in a knowledge-sharing environment. The article presents results already achieved since the Project began in 2009, especially the experience with the Scientific Creativity Workshop, an extension course with online activities that provides the participants with an opportunity to meet and work with approaches and methodologies in the field of Information Science.
\end{abstract}

Keywords: Information science. Information skills. Continuing education. Information scheme. Intellectual technologies.

1 Apoio do Conselho Nacional de Desenvolvimento Científico e Tecnológico (Edital Universal 2009 e PIBIC) e do Programa de Bolsas de Extensão da Universidade Federal da Paraíba.

2 Universidade Federal da Paraíba, Departamento de Comunicação Social. Campus I, Jardim Cidade Universitária, 58051-900, João Pessoa, PB, Brasil. Correspondência para/Correspondence to: I.M. FREIRE. E-mail: <isafreire@globo.com>.

3 Universidade Federal da Paraíba, Programa de Pós-Graduação em Ciência da Informação. João Pessoa, PB, Brasil.

- Universidade Federal da Paraíba, Departamento de Ciência da Informação. João Pessoa, PB, Brasil.

Recebido em 6/9/2010, reapresentado em 10/5/2011 e aceito para publicação em 21/6/2011. 


\section{Introdução}

O presente trabalho visa descrever as ações de pesquisa e extensão desenvolvidas no Projeto Laboratório de Tecnologias Intelectuais (LTi), com vistas ao desenvolvimento de atividades que facilitem o acesso livre à informação científica e tecnológica e, ao mesmo tempo, promovam competências em tecnologias intelectuais para produção e uso da informação.

O LTi iniciou suas atividades em 2009, com o apoio do Conselho Nacional de Desenvolvimento Científico e Tecnológico (CNPq - edital 014/2009 Universal), do Programa Institucional de Bolsas de Iniciação Científica (PIBIC) e do Programa de Bolsas de Extensão (PROBEX) da Universidade Federal da Paraíba (UFPB). Este último é mantido com recursos da própria Universidade, com o propósito de contribuir para a formação acadêmica dos estudantes dos cursos de graduação e das escolas técnicas, a partir da experiência em extensão universitária.

A abordagem metodológica utilizada no LTi tem um caráter participativo, tanto pela articulação com o espaço socioinstitucional quanto pela abordagem teórica. Nesse sentido, adota-se a premissa da responsabilidade social da Ciência da Informação conforme Wersig \& Neveling (1995) e Freire (2001), bem como os construtos do regime de informação proposto por González de Gómez (1999a,b, 2002, 2003a,b); das tecnologias intelectuais e inteligência coletiva, de Lévy (1994, 2000); das competências em informação, de Belluzzo (2001), Hattschbach (2002) e Dudziak (2003); de projeto, de Lück (2001) e Freire (2004) e de pesquisa-ação, como proposto porThiollent (1997) e experimentado por Freire, G.H. (1998),

Espírito Santo (2003) e Freire, I.M. (2006 e 2009), no campo da Ciência da Informação.

Como urdidura para os fios do presente relato, é apresentada a seguir a perspectiva a partir da qual se propõe promover uma integração entre pesquisa-ensino-extensão, no escopo do LTi. Dessa forma, espera-se ampliar a discussão sobre o valor da informação na sociedade contemporânea e sobre a necessidade de democratizar o acesso a fontes e competências informacionais relevantes.

\section{A teia conceitual}

O contexto deste estudo, no tear interdisciplinar da Ciência da Informação, será tecido a partir da urdidura constituída por três fios conceituais, dentre os quais o de "tecnologias intelectuais", proposto por Lévy (1994), figura como construto operatório. Pois, acompanhando Lévy (1994, p.42), o presente estudo considera essas tecnologias "[...] tanto as formas de expressão simbólica [...] quanto às tecnologias de informação em si mesmas (p.ex., a escrita em tabuinhas de barro, as iluminuras medievais, a imprensa e os computadores)". Ainda de acordo com Lévy (1994, p.42), essas tecnologias intelectuais:

[...] situam-se fora dos sujeitos cognitivos, como
este computador sobre minha mesa ou este
[texto] em suas mãos. Mas elas também estão
entre os sujeitos como códigos compartilhados,
textos que circulam, programas que copiamos,
imagens que imprimimos e transmitimos por
via hertziana. [...] As tecnologias intelectuais estão
ainda nos sujeitos, através da imaginação e da
aprendizagem (grifos nossos).

No enunciado acima, identificam-se as tecnologias intelectuais de organização, processamento e busca de informação relevante para um dado grupo de usuários na sociedade contemporânea, produzidas no campo da Ciência da Informação.

\section{A perspectiva do regime de informação}

O segundo fio da teia conceitual subjacente a este estudo é constituído pelo construto de "regime de informação", proposto por González de Gómez (1999a,b; 2002; 2003a,b; 2004), que designa o modo de produção informacional numa formação social, no qual ficaria estabelecido quem são os sujeitos, as organizações, as regras e as autoridades normativas no campo da informação. Trata-se do conjunto de determinações em que estão definidos os elementos que compõem o fluxo estrutural da produção, organização, comunicação e transferência de informações em um dado espaço social.

Na perspectiva do regime de informação, a Ciência da Informação:

[é] aquela que estuda fenômenos, processos, construções, sistemas, redes e artefatos de informação, enquanto 'informação' for definida por 
ações de informação, as quais remetem aos atores que as agenciam aos contextos e situações em que acontecem e aos regimes de informação em que se inscrevem (González de Gómez, 2003b, p.61).

O construto "regime de informação" é proposto por González de Gómez (1999a, p.24) como sendo:

[o] com-junto mais ou menos estável de redes sociocomunicacionais formais e informais nas quais informações podem ser geradas, organizadas e transferidas de diferentes produtores, através de muitos e diversos meios, canais e organizações, a diferentes destinatários ou receptores, sejam estes usuários específicos ou públicos amplos. [...] [o qual] está configurado, em cada caso, por plexos de relações plurais e diversas: intermediáticas; interorganizacionais e intersociais. [Sendo constituído, assim,] pela figura combinatória de uma relação de forças, definindo uma direção e arranjo de mediações comunicacionais e informacionais dentro de um domínio funcional (saúde, educação, previdência, etc.), territorial (município, região, grupo de países) ou de sua combinação.

Nesse modelo - e enquanto ação de informação - a informação se refere a um conjunto de estratos heterogêneos e articulados que se manifestam através de três modalidades:

a) mediação $0^{5}$ - quando atrelada aos fins e orientação de uma outra ação. Quando a informação enquanto tal forma parte de uma ação de informação que intervém como mediação no contexto de outra ação social, [pode-se] dizer que o sujeito dessa ação de informação é um "sujeito funcional", cujas práticas serão definidas pelo contexto acional em que atua, dentro das múltiplas atividades sociais. [Portanto], seu domínio de constituição é a praxis (Gonzalez de Goméz, 2003b, p.36).

b) formação - quando orientada à informação não como um meio, mas como sua finalização, sendo: [...] Gerada por sujeitos sociais heurísticos ou "experimentadores", transformando os modos culturais de agir e de fazer, nas artes, na política, na ciência, na indústria e no trabalho, iniciando um novo domínio informacional. Trata-se de uma manifestação no domínio da poiesis (Gonzalez de Goméz, 2003b, p.36).

c) relação - quando busca intervir em uma outra ação para dela obter direção e fins ${ }^{6}$. Diz-se quando uma ação de informação intervém em outra ação, duplicando o espaço de realização de uma outra ação de informação, "o qual alarga nas formas de descrição, da facilitação, do controle ou do monitoramento, falamos assim de ações relacionais realizadas por sujeitos articuladores ou relacionantes" [Portanto agem no domínio da legein] (González de Gómez, 2003b, p.37).

O Quadro 1 mostra a constituição das ações de informação em um dado regime de informação, bem como as relações entre atores (executores das ações), meios e fins, conforme apresentado por González de Gómez (2003b, p. 37):

São, também, constituintes de um regime de informação (Figura 1):

- Os dispositivos de informação, que podem ser considerados um meanismo operacional ou um conjunto

Quadro 1. Teleologia das ações de informação.

\begin{tabular}{llll}
\hline Ações de Informação & Atores & Atividades & [Finalidade] \\
\hline Ação de Mediação & $\begin{array}{l}\text { Sujeitos Sociais Funcionais } \\
\text { (práxis) }\end{array}$ & Atividades Sociais Múltiplas & Transformar o mundo social ou natural \\
Ação Formativa & Sujeitos Sociais & Atividades Heurísticas e de Inovação & Transformar o conhecimento para trans- \\
ou Finalista & Experimentadores & formar o mundo \\
Ação Relacional & Sujeitos Sociais & Atividades Sociais de Monitoramento, Transformar a informação e a comu- \\
Inter-Meta-Pós-mediática & Articuladores e Reflexivos & Controle e Coordenação & nicação que orientam o agir coletivo \\
\hline
\end{tabular}

Fonte: Gonzalez de Gomez (2003b).

5 No caso do LTi, as mídias direta ou indiretamente vinculadas ao Projeto, como o site do LTi, a Revista PBCIB, o blog De Olho na Cl, bem como os tutoriais disponibilizados na web.

- A ação de informação constituída pelo LTi está atrelada aos fins e orientação da tríplice atuação da universidade pública, qual seja ensino, pesquisa e extensão. 


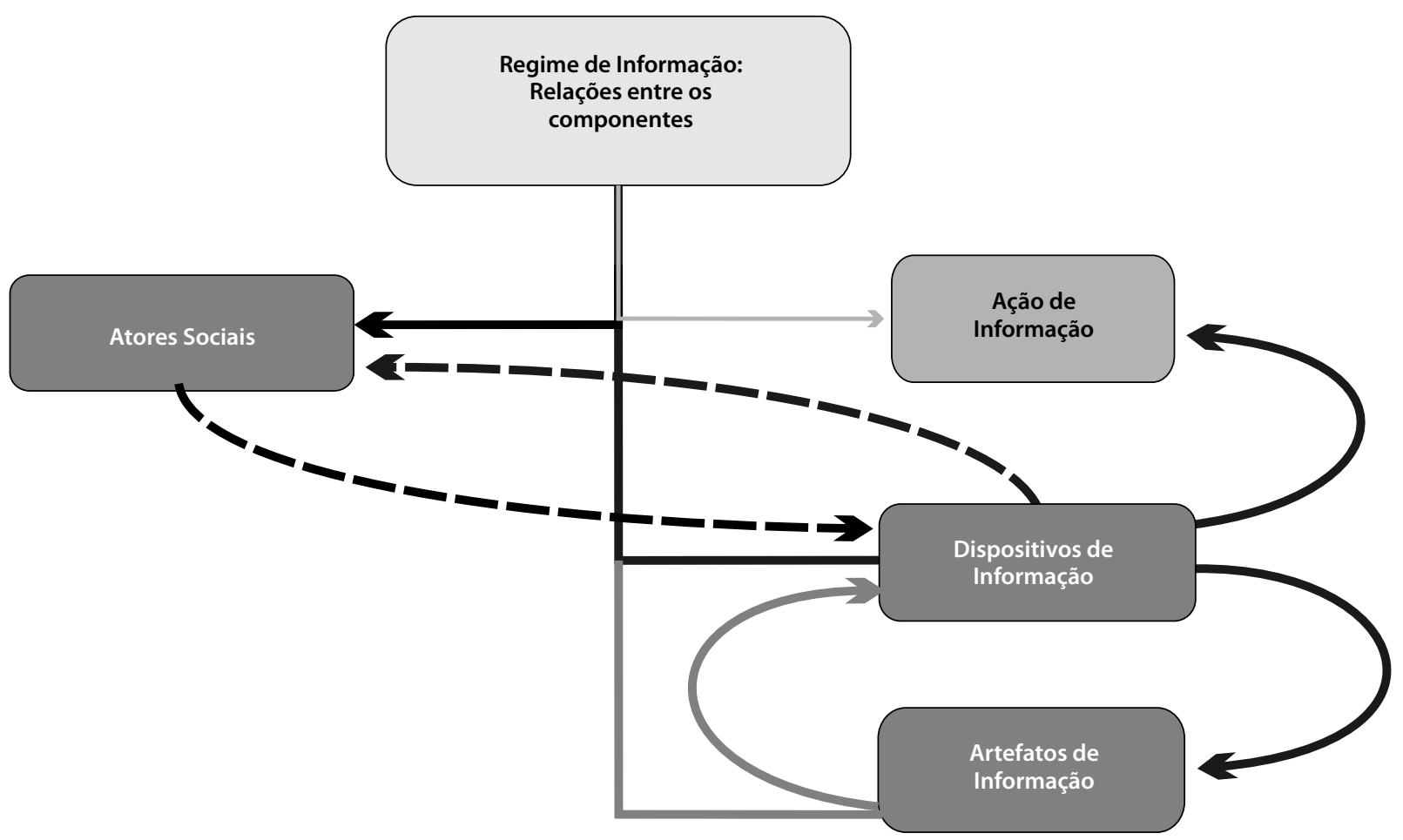

Figura 1. Representação gráfica das relações entre os componentes do regime de informação.

Fonte:Delaia (2008).

de meios, composto de regras de formação e de transformação desde o seu início, ou, como González de Gómez (1997, p.63) exemplifica, como"um conjunto de produtos e serviços de informação e das ações de transferência de informação".

- Os atores sociais, "[...] que podem ser reconhecidos por suas formas de vidas e constroem suas identidades através de ações formativas existindo algum grau de institucionalização e estruturação das ações de informação" (González de Gómez, 2003b, p.35).

- Os artefatos de informação, que são os modos tecnológicos e materiais de armazenagem, processamento e transmissão de dados, mensagens e informações (González de Gómez, 2002, 2003b).

Nesse contexto, as ações de pesquisa e de informação integram um mesmo domínio de orientações estratégicas e, como consequência, "[...] a política e a gestão da informação formarão parte do mesmo plano decisional e prospectivo ao qual pertence a política e a gestão da ciência e tecnologia (C\&T)"(González de Gómez, 2003b, p.61).

Com essa abordagem, este estudo entende que o campo da Ciência da Informação pode proporcionar recursos teóricos e tecnológicos que promovam as competências necessárias à socialização da informação. Nesse caso, é possível propor uma ação que possibilite a união desses contextos em um espaço social onde cientistas e profissionais da informação possam desenvolver ações com vistas à gestão de recursos para promover a inclusão na Sociedade da Informação e do Conhecimento. E é justamente isso que vem sendo realizado no âmbito do Lti por meio das ações interligadas de pesquisa, ensino e extensão, como pode ser apreendido na Figura 2.

Essas ações, no que diz respeito à capacitação para o uso de tecnologias intelectuais e digitais para produção e comunicação da informação, vem possibilitando a busca, recuperação, propagação e apropriação de informações por diversos grupos sociais, contribuindo, assim, para minimizar as desigualdades socioinformacionais. 


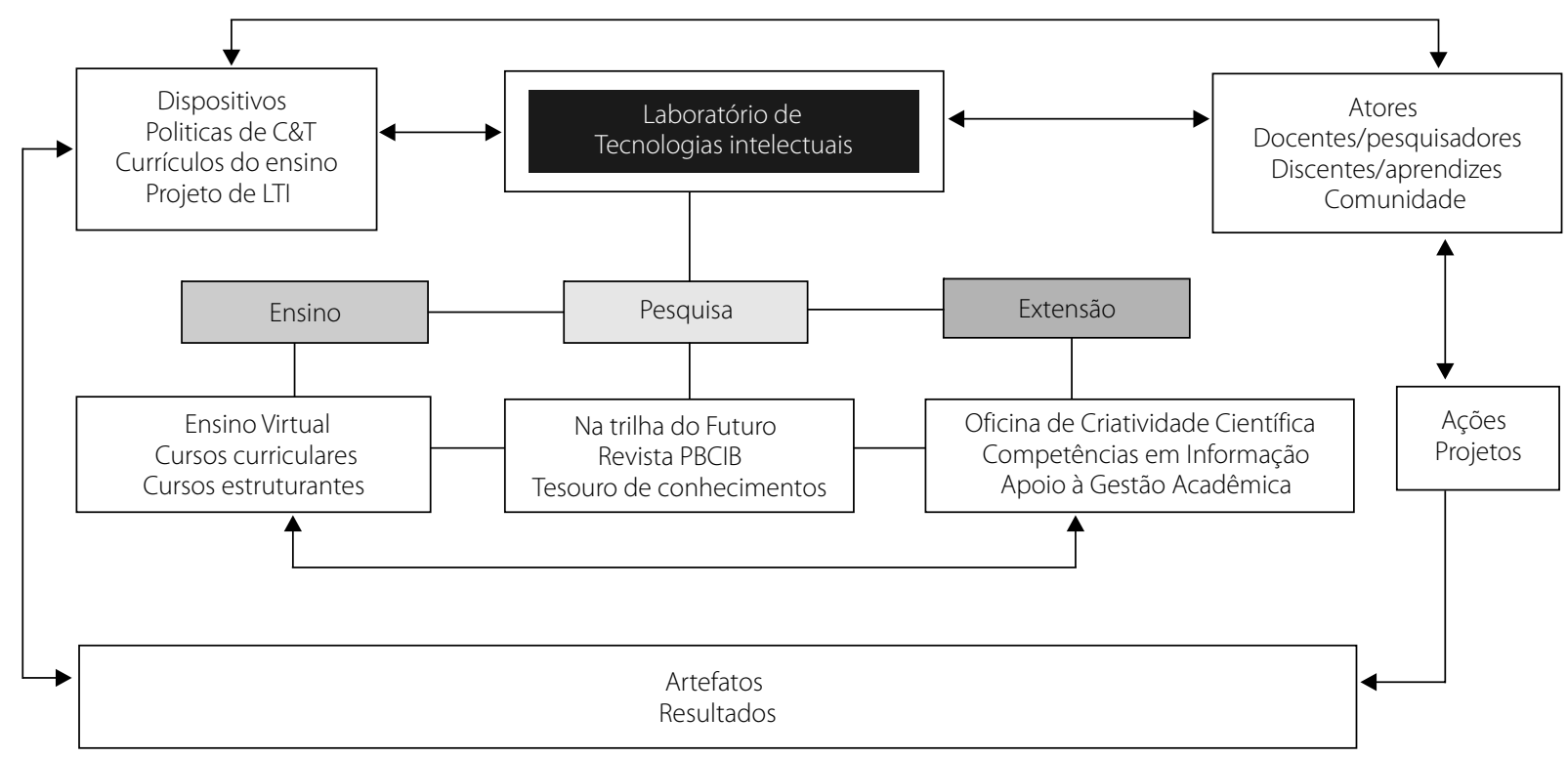

Figura 2. Diagrama da rede de projetos do LTi na perspectiva do regime de informação.

Fonte: Freire (2010)

\section{As competências em informação}

Em 1989, o Comitê Presidencial da American Library Association (ALA) publicou um relatório reconhecendo a importância da Information Literacy para a manutenção de uma sociedade democrática. No documento, são definidas como competentes em informação pessoas capazes:

[...] de reconhecer quando a informação é necessária e [com] a habilidade de localizar, avaliar e usar efetivamente esta informação [Essas pessoas] aprenderam como aprender. Elas sabem como aprender porque sabem como a informação é organizada, como encontrá-la e como usar a informação de forma que os outros também possam aprender com ela (American Library Association, 1989).

Dois anos depois, Kuhlthau (1991) contribuiu para a fundamentação teórica da Information Literacy com um estudo sobre o comportamento dos estudantes, concluindo que não se trata apenas de possuir habilidades, mas, sobretudo, de uma maneira de aprender, ressaltando que"a busca de informação é um processo de construção que envolve a experiência de vida, os sentimentos, bem como os pensamentos e as atitudes de uma pessoa" (Kuhlthau, 1991, p.362).
Logo depois, Doyle (1994) publicou um trabalho em que narra a história, o desenvolvimento e a importância da Information Literacy como aspecto significante para a organização e o desenvolvimento da sociedade contemporânea. O estudo apresenta um levantamento dos atributos para uma pessoa ser considerada competente em informação, os quais, de acordo com Doyle (1994, p.3), são:

- reconhecer que uma informação precisa e correta é a base para uma tomada de decisão inteligente;

- reconhecer a necessidade de informação;

- formular questões baseadas em necessidades de informação;

- identificar fontes potenciais de informação;

- desenvolver estratégias de pesquisa bem sucedidas;

- saber acessar diversas fontes de informação, incluindo o computador e outras tecnologias;

- avaliar a informação;

- organizar a informação para aplicação prática;

- integrar informações novas a conhecimentos já adquiridos;

- utilizar a informação de uma forma crítica e para a resolução de problemas.

$\overline{7}$ Adota-se aqui a proposta por Hatschbach (2002) como tradução para Information Literacy. 
No Brasil, Caregnato (2000) abordou o tema, destacando que tradicionalmente as bibliotecas oferecem serviços de treinamento em busca de informação para seus usuários, ou programas de instrução integrados às disciplinas dos cursos de graduação, oficinas, palestras, atendimento individualizado e outros formatos. Caregnato, (2000, p.49) ressalta que não há um consenso sobre a utilização da terminologia sobre o tema, no Brasil:

[...] expressões como treinamento de usuários,
instrução de usuários, instrução bibliográfica,
educação de usuários e desenvolvimento de
habilidades informacionais, são usadas na lite-
ratura especializada e na prática profissional de
uma forma quase indiscriminada.

Novellino (2000, p.43), ao tratar da questão da transferência da informação através de seus contextos e usos, contribui para essa discussão ao afirmar que:

[...] não há um espaço de transferência da informação, mas uma gama de espaços: os mais tradicionais como bibliotecas, centros de documentação e bases de dados geridos por instituições acadêmicas e empresas; os alternativos como os centros de documentação inseridos em organizações da sociedade civil voltados a disseminar informação àqueles excluídos dos sistemas de informação tradicionais; e aqueles gerados mais recentemente a partir das novas tecnologias como as redes eletrônicas.

Baseada na literatura especializada, Hattschbach (2002) propõe que as competências em informação sejam vistas como habilidades e capacidades em utilizar a informação e o conhecimento sobre sua sistemática e movimento. Além da capacitação no uso das ferramentas para a recuperação da informação, a autora inclui nesse conjunto o conhecimento de fontes, o pensamento crítico, a formulação de questões, a avaliação, a organização e a utilização da informação.

Nesse sentido, Belluzzo (2001), em trabalho sobre a questão da educação na Sociedade da Informação, afirma que a "gestão da informação - nos diferentes níveis: pessoais, organizacionais e sociais - é o grande desafio dos tempos atuais, constituindo-se no próximo estágio de alfabetização do homem". Belluzzo destaca que, entre outras competências, o processo de ensino-aprendizagem deveria centrar-se "na fluência científica e tecnológica e no saber utilizar a informação, criando novo conhecimento".
Assim, a abordagem de competências em informação expande a noção da educação ou treinamento de usuários, até então restrita à formação para a utilização da informação em ambientes formais de estudo e pesquisa, como escolas, universidades, bibliotecas e centros de informação. Nessa perspectiva, é possível abordar, além das habilidades para a busca de informação em bibliotecas e bases de dados, as habilidades cognitivas e tecnológicas de estudo e pesquisa para uso da informação e sua transformação em novo conhecimento.

\section{A rede de projetos do LTi}

A abordagem metodológica do Projeto Laboratório de Tecnologias Intelectuais (LTi) pauta-se no caráter interativo presente tanto nas tecnologias digitais de informação e comunicação quanto na participação da comunidade no processo de construção de interfaces de organização e comunicação da informação. Nesse sentido, o Projeto adota o modelo da pesquisa-ação de Thiollent (1997).

\section{Método de abordagem}

A escolha da pesquisa-ação traduz a tentativa de abordar a comunicação da informação como ação transformadora, no sentido que lhe atribui Araújo (1994), criando espaço para a intervenção empírica em uma dada situação.

Na América Latina, a pesquisa-ação também foi formulada em termos de "pesquisa participante", sendo utilizada como instrumento entre populações carentes, "com seus problemas educacionais, culturais ou de consciência política" (Thiollent, 1997, p.21). No Brasil, tem sido pensada e aplicada no contexto das organizações e instituições.

Mas, se toda pesquisa-ação possui um caráter participativo, pelo fato de promover ampla interação entre pesquisadores e sujeitos representativos da situação investigada, o que diferencia a pesquisa-ação da pesquisa participante?

Segundo Thiollent (1997), a pesquisa-ação"consiste essencialmente em acoplar pesquisa e ação em um processo no qual os atores implicados participam, junto com 
os pesquisadores, para chegarem interativamente a elucidar a realidade em que estão inseridos" (Thiollent, 1997, p.15). Nessa perspectiva, entende-se por "ator" qualquer grupo de pessoas que dispõe de certa capacidade de ação coletiva consciente em um contexto social delimitado, seja um grupo informante no meio de uma organização, seja um grupo formalmente constituído. Já a "participação" é encarada como propriedade emergente do processo, e não como um a priori. A metodologia requer clara definição de objetivos em termos de pesquisa e de ação, e o processo não existe de forma totalmente padronizada, pois, dependendo da situação social ou do quadro organizacional em que se aplicam os procedimentos, pode variar a ordenação das etapas no decorrer da pesquisa.

Buscando uma visão sintética, Dubost (1987, p.37) examinou várias concepções de pesquisa-ação vinculadas a tradições norte-americanas e europeias, formulando sua própria definição como "ação deliberada visando a uma mudança no mundo real, realizada em escala restrita, inserida em um projeto mais geral e submetida a certas disciplinas para obter efeitos de conhecimento e de sentido".

O Projeto LTi integrou a abordagem de Dubost (1987) à visão cooperativa de Desroche (1990, p.52), que define a pesquisa-ação como uma pesquisa:

[...] na qual os autores de pesquisa e os atores sociais se encontram reciprocamente implicados: os atores na pesquisa e os autores na ação. [...] na pesquisa-ação os atores deixam de ser simplesmente objeto de observação, de explicação ou de interpretação. Eles tornam-se sujeitos e parte integrante da pesquisa, de sua concepção, de seu desenrolar, de sua redação e de seu acompanhamento.

Tema central da metodologia de pesquisa-ação, a articulação entre pesquisa e ação é concebida por Desroche de modo diferenciado e em função de uma tipologia das formas de participação. Desse modo, como pesquisa inserida na ação, a pesquisa-ação comportaria três aspectos simultâneos:

a) "Pesquisa SOBRE os atores sociais, suas ações, transações, interações", quando seu objetivo é a explicação; b) "Pesquisa PARA dotar de uma prática racional as práticas espontâneas", quando seu objetivo é a aplicação;

c) "Pesquisa POR, ou melhor, PELA ação, isto é, assumida por seus próprios atores (autodiagnóstico e autoprognóstico) tanto em suas concepções como em sua execução e seus acompanhamentos", quando seu objetivo é a implicação (Thiollent, 1997, p.37).

Para Thiollent (1997), a simultaneidade desses três aspectos impede que a pesquisa-ação seja confundida com a "observação participante", que se limita a uma pesquisa SOBRE, embora o pesquisador compartilhe, o mais possível, do contexto dos participantes. Por sua vez, aplicação se relaciona à ideia de transpor conhecimentos gerais de uma teoria para um contexto concreto, pois nem sempre uma teoria dá conta dos problemas da situação concreta; assim, o autor propõe pensar a pesquisa como relação entre teoria e prática ${ }^{8}$. Ele lembra que o uso do termo explicação deve incluir o conceito de compreensão, associado às metodologias qualitativas ou interpretativas. No que diz respeito à implicação, Thiollent (1997) distingue duas características principais: a efetividade, ou reciprocidade, do relacionamento entre pesquisadores e atores, e a clareza dos posicionamentos de cada parte envolvida na pesquisa no plano ético. O Projeto LTi propõe desenvolver os três aspectos simultâneos da pesquisa-ação, conforme descritos anteriormente.

\section{Procedimentos}

O Laboratório de Tecnologias Intelectuais (LTi) é implementado através de uma rede de projetos (Freire, 2004), em correspondência com as atividades acadêmicas da UFPB e em conformidade com o "método de projeto", considerado por Lück (2001, p.13) como uma"ferramenta básica do gestor, que [...] fundamenta, direciona e organiza a ação de sua responsabilidade [e] possibilita o seu monitoramento e avaliação". Nesta perspectiva, projeto é definido como:

[...] um conjunto organizado e encadeado de ações de abrangência e escopo definidos, que focaliza aspectos específicos a serem abordados

\footnotetext{
- Este estudo entende a"pesquisa aplicada"de Thiollent como a "pesquisa prática"de Demo (2000), ou ligada à prática de usar o conhecimento científico para fins explícitos de intervenção numa dada situação.
} 
num período determinado de tempo, por pessoas associadas e articuladoras das condições promotoras de resultados (Lück, 2001, p.27).

A rede de projetos do LTi é constituída por propostas de ações de informação no âmbito das três linhas de atuação universitária: ensino, pesquisa, extensão. Professores do Departamento de Ciência da Informação (DCI) e do Programa de Pós-Graduação em Ciência da Informação (PPGCI) da UFPB participam da rede, por meio de projetos que estão em desenvolvimento, elaboração ou fase de discussão, em uma das linhas de atuação da universidade. Nos três níveis de atividades do LTi, essa rede de projetos visa alcançar os seguintes objetivos:

Na pesquisa [inovação e desenvolvimento]: proposição de modelo de ação de informação na perspectiva da universidade; implementação de projeto-piloto (experimentação e avaliação do modelo); comunicação científica (oficinas, seminários, comunicações em eventos, artigos).

No ensino [apoio e complementação]: realização de oficinas de tecnologias intelectuais (fundamentação teórica e metodológica para pesquisa científica, competências em informação - EAD); realização de oficinas de tecnologias intelectuais digitais (introdução à informática, sistemas de processamento e recuperação da informação).

Na extensão [responsabilidade social]: realização de oficinas de acesso a fontes acadêmicas de informação na Internet (portal de periódicos científicos, portais de informação científica), qualidade do trabalho acadêmico.

Dessa forma, espera-se que as ações desenvolvam entre os participantes uma sinergia para o trabalho a ser empreendido, com o propósito de promover benefícios às pessoas e organizações. Destarte, o Projeto representa a oportunidade para os pesquisadores tecerem, no tear da Ciência da Informação, um padrão que (re)una informação, comunicação e computação, em nível da integração pesquisa, ensino e extensão na práxis acadêmica.

\section{Ações de extensão no LTi}

A seguir, é apresentado as ações de extensão realizadas no âmbito do LTi, quais sejam os projetos Oficina de criatividade científica no campo da informação, com a terceira finalizada em agosto de 2011, Monitoria virtual e Gerenciamento de blogs (realizados em 2010).

\section{Oficina de criatividade científica}

A Oficina de criatividade cientifica no campo da informação tem sua origem motivada por dois fatores: 1) a percepção da necessidade de capacitação, no campo da ciência da informação e da metodologia da pesquisa, de um conjunto significativo de candidatos ao Mestrado do Programa de Pós-Graduação em Ciência da Informação, oriundos das mais diversas áreas do conhecimento; 2) o desejo de contribuir, mediante ações de informação, para o desenvolvimento de competências em informação capazes de alterar trajetórias de vidas.

No que se refere à estrutura, metodologia e funcionamento, a Oficina está estruturada, em 60h/aula, distribuídas em 20 encontros semanais e sequenciais de 3h/aula, no período de maio a agosto. Os encontros são desenvolvidos mediante aulas expositivas, dinâmicas de grupo, exercícios extraclasse e palestras, com vistas ao desenvolvimento, discussão e aproveitamento das oportunidades de aprendizagem propiciadas. Os participantes são inscritos em um grupo virtual, que se transforma no mural do curso, onde publicam comentários sobre textos, apresentações de pesquisadores e outros temas de interesse comum.

Embora o público atendido seja heterogêneo no que se refere à biografia individual, a maioria são profissionais recém-graduados ou com certo tempo de atuação em suas áreas, que desejam se candidatar à seleção para o Mestrado do PPGCl da UFPB.

No que se refere ao desempenho, a Tabela 1 permite visualizar quantitativamente a eficácia dessa ação de informação, descrevendo o desempenho dos participantes da Oficina, inscritos na seleção do PPGCI/UFPB nos anos de 2009 e 2010.

Nota-se inicialmente que, do total de 22 alunos da Oficina inscritos na seleção 2009 do PPGCl, 7 (31,8\% ) conseguiram aprovação na primeira fase do processo seletivo, que diz respeito à análise da pertinência, adequação e relevância da proposta de pesquisa apresentada no projeto. Na seleção para a turma 2010, o número subiu para 10 , ou $52,0 \%$ dos inscritos, o que representa um incremento da ordem de 20 pontos percentuais. Esse aumento parece representar a consecução do objetivo principal desta ação de informação, qual seja: possibilitar, por meio de uma práxis educativa de compartilhamento de competências informacionais, o acesso às instâncias de saber institucionalizadas. 
A consecução desse objetivo ainda fica mais evidente quando se comparam aqueles que participaram da Oficina e foram aprovados em todas as fases, com aqueles que não participaram, como demonstra a Tabela 2.

Como se pode observar, enquanto no processo seletivo 2009 a Oficina foi responsável por 20,0\% do total dos candidatos aprovados, em 2010 obteve-se um incremento de 33 pontos percentuais, uma vez que os candidatos aprovados que participaram da Oficina ocuparam 52,9\% do total das vagas oferecidas no concurso de seleção para o Mestrado do PPGCI/UFPB.

\section{Monitoria Virtual}

No projeto da rede do LTi, desenvolvido em 2010, foi realizada uma ação de extensão para apoio à melhoria da qualidade acadêmica na graduação na UFPB, tendo como objetivo o desenvolvimento de cursos curtos tutoriais on-line para transferência de tecnologias intelectuais de apoio ao trabalho acadêmico. Outros objetivos, também alcançados ao final do Projeto, foram: a) identificação de valores e saberes que contribuam para o aprendizado em ambientes virtuais; b) realização de trocas produtivas de conhecimentos e experiências entre pesquisadores e aprendizes de pesquisa; c) contribuição para uma reflexão sobre políticas para o desenvolvimento de modelos de ação de informação e competências em informação na web.

Como tema para os cursos tutoriais em 2010, foram selecionadas quatro tecnologias intelectuais de apoio ao trabalho acadêmico, considerando o estudo sistemático de textos científicos e a identificação das fontes de pesquisa: fichamento de textos; referências, em conformidade com a NBR 6023; resumos, em conformidade com a NBR 6028; citações, em conformidade com a NBR 10520.

No decorrer dos cursos, os alunos de graduação selecionados como monitores receberam treinamento na tecnologia da plataforma Moodle (Modular ObjectOriented Dynamic Learning Environment), como contribuição ao desenvolvimento de suas próprias competências em informação.

Como resultado, nas temáticas definidas no Projeto, foram produzidos materiais para desenvolvimento de cursos de curta duração (até 12h/aula) na Plataforma Moodle, para uso na disciplina Metodologia do Trabalho

Tabela 1. Desempenho dos participantes da Oficina inscritos na seleção do Mestrado no total de inscritos na seleção do PPGCI da UFPB nos anos de 2009 e 2010

\begin{tabular}{|c|c|c|c|c|}
\hline \multirow{2}{*}{ Participantes da Oficina inscritos na seleção do Mestrado } & \multicolumn{2}{|c|}{2009} & \multicolumn{2}{|c|}{2010} \\
\hline & $n^{\circ}$ & $\%$ & no & $\%$ \\
\hline Não aprovados & 10 & 45,5 & 3 & 12,0 \\
\hline Aprovados apenas na fase "projeto" & 7 & 31,8 & 13 & 52,0 \\
\hline Aprovados no Mestrado & 5 & 22,7 & 9 & 36,0 \\
\hline Total & 22 & 100,0 & 25 & 100,0 \\
\hline
\end{tabular}

Fonte: Relatórios PROBEX, 2009 e 2010.

PPGCI: Programa de Pós-Graduação em Ciência da Informação; UFPB: Universidade Federal da Paraíba.

Tabela 2. Peso dos participantes da Oficina aprovados no Mestrado no total de aprovados na seleção do PPGCI da UFPB nos anos de 2009 e 2010 .

\begin{tabular}{|c|c|c|c|c|}
\hline \multirow{2}{*}{ Aprovados na seleção do Mestrado } & \multicolumn{2}{|c|}{2009} & \multicolumn{2}{|c|}{2010} \\
\hline & $n^{\circ}$ & $\%$ & $n^{\circ}$ & $\%$ \\
\hline Participantes da Oficina & 5 & 20,0 & 9 & 52,9 \\
\hline Não participantes da Oficina & 20 & 80,0 & 8 & 47,1 \\
\hline Total & 25 & 100,0 & 17 & 100,0 \\
\hline
\end{tabular}

Fonte: Relatórios PROBEX, 2009 e 2010

PPGCI: Programa de Pós-'Graduação em Ciência da Informação; UFPB: Universidade Federal da Paraíba. 
Científico, oferecida pelo Departamento de Ciência da Informação aos cursos de graduação da UFPB. Para o futuro, vislumbra-se a continuidade da realização de cursos de extensão vinculados, direta ou indiretamente, ao ensino de graduação e pós-graduação no campo da Ciência da Informação.

\section{Gerenciamento de blogs}

O curso de Gerenciamento de blogs foi uma ação de extensão do LTi, desenvolvida em 2010 mediante parceria com o Programa de Pós-Graduação em Ciência da Informação (PPGCI) da Universidade Federal da Paraíba (UFPB).

Destinado a moradores da Comunidade Santa Clara (CSC), localizada na cidade de João Pessoa (PB), o curso teve como objetivo realizar treinamento na produção e gerenciamento do blog da comunidade. O Projeto foi realizado no âmbito da pesquisa-dissertação "A inclusão de comunidades na sociedade da informação: uma proposta de trabalho na Comunidade Santa Clara"(Faria, 2011), que teve como objetivo construir de forma participativa um sítio virtual, de modo a facilitar às futuras gerações o acesso ao "tesouro de conhecimentos" das pessoas depositárias da memória social e do saber daquela localidade. Para produção do blog foi escolhida a tecnologia WordPress, uma plataforma semântica de vanguarda para publicação pessoal, com foco na estética, nos padrões web e na usabilidade, salientando-se que se trata de um software livre.

Durante o treinamento, os participantes puderam verificar como o blog da Comunidade Santa Clara foi desenvolvido; como inserir notícias, fotos e vídeos; e o que deverá ser postado. Os textos a serem publicados devem ser de interesse da CSC, como a história dos moradores e da comunidade, os eventos e festas ali ocorridos, e as ações promovidas pela associação de moradores.

Os participantes do treinamento receberam informações sobre os elementos mais importantes para o bom funcionamento e desempenho do blog, quais sejam a linguagem dos textos, direta e atenta às normas gramaticais; o tamanho dos textos, sempre curtos e com o foco na temática de que trata o blog; o cuidado com os direitos autorais: ao publicar textos ou imagens retirados de outras fontes, deve-se sempre citá-las.

Outro resultado do Projeto foi a produção de um tutorial para criação de blogs, usando a plataforma WordPress, disponível no sítio virtual do LTi, em <http:// dci.ccsa.ufpb.br/lti/?download=Tutorial.pdf>.

\section{Considerações Finais}

No Laboratório de Tecnologias Intelectuais a proposta é caminhar para a noção de inteligência coletiva, utilizando-se uma rede, com ênfase na relação entre os elementos e na forma como se entrelaçam, se complementam e se modificam. Enfim, as tecnologias intelectuais podem misturar-se, interagir, integrar-se ou separar-se, dependendo das atividades desenvolvidas e das ações realizadas.

Com base nas experiências vividas durante as atividades desses dois anos de implementação do LTi, pôde-se constatar a possibilidade de uma aprendizagem cooperativa, com atitudes e práticas interdisciplinares, bem como a grande versatilidade tecnológica que pode auxiliar no desenvolvimento das atividades e sua expansão para contextos sociais mais amplos.

Nesse sentido, a proposta do Laboratório de Tecnologias Intelectuais representa uma contribuição à política de inclusão digital da Universidade Federal da Paraíba, que tem como finalidade promover o acesso de docentes e discentes à rede Internet, propiciando-lhes oportunidades de adquirir competências para buscar, organizar e utilizar a informação científica. A dinâmica de desenvolvimento dos projetos considerados no LTi tem possibilitado a busca por informações a respeito de temas de interesse para a sociedade, além de evidenciar a presença de diferentes áreas do conhecimento no processo, promovendo a interdisciplinaridade existente na própria Ciência da Informação.

Destarte, o LTi se propõe a educar para o uso dos meios digitais segundo aspectos éticos e morais, priorizando a concepção de que tais recursos tecnológicos devem dar suporte a um processo de ensino e aprendizagem comprometido com a educação para a cidadania. Para isto, deve-se lançar mão de ações e projetos 
orientados para fomentar o trabalho colaborativo, capaz de suscitar o planejamento e a produção coletiva. Somente assim será possível atingir o objetivo de formar competências em informação, algo extremamente necessário para lidar com o excesso, dispersão e superficialidade dos conteúdos informacionais disponíveis na web.

\section{Referências}

AMERICAN LIBRARY ASSOCIATION. Presidential Committee on Information Literacy. Chicago: ALA, 1989. (Final Report). Available from: <http://www.ala.org/acrl/nili/ilit1st.html>. Cited: 26 Aug. 2006.

BELLUZZO, R.C.B. A information literacy como competência necessária à fluência científica e tecnológica na sociedade da informação: uma questão de educação. In: SIMPÓSIO DE ENGENHARIA DA PRODUÇÃO DA UNESP, 7., 2001, São Paulo. Anais... São Paulo: Unesp, 2001. Disponível em: <http://www. simpep. feb.unesp.br/ana8.html>. Acesso em: 13 mar. 2002.

CAREGNATO, S.E. O desenvolvimento de habilidades informacionais: o papel das bibliotecas universitárias no contexto da informação digital em rede. Biblioteconomia \& Comunicação, v.8, p.47-55, 2000.

DELAIA, C.R. Subsídios para uma política de gestão da informação na EMBRAPA Solos. 2008. Dissertação (Mestrado Ciência Informação) - Universidade Federal Fluminense, Niterói, 2008.

DESROCHE, H. Entreprendre d'apprendre: d'une autobiographie raisonnée aux projets d'ue recherche-action. Paris: Ed. Ouvrières, 1990.

DOYLE, C. Information literacy in information society: a concept for the information age. New York: ERIC Clearinghouse on Information \& Technology, 1994.

DUBOST, J. L'intervention psycho-sociologique. Paris: PUF, 1987.

DUDZIAK, E.A. Information literacy: princípios, filosofia e prática. Ciência da Informação, v.32, n.1, p.23-35, 2003.

DUDZIAK, E.A. Os faróis da sociedade de informação: uma análise crítica sobre a situação da competência informacional no Brasil. Informação \& Sociedade, v.18, n.2, p.41-53, 2008.

DUDZIAK, E.A.; BELLUZZO, R.C.B. Educação, informação e tecnologia na sociedade contemporânea: diferenciais à inovação? Revista Brasileira de Biblioteconomia e Documentação: Nova Série, v.4, n.2, p.44-51, 2008.

ESPÍRITO SANTO, C.C. "Quissamã somos nós": pesquisa participante para construção de hipertexto sobre identidade cultural. 2003. Dissertação (Mestrado em Ciência da Informação) - Universidade Federal do Rio de Janeiro, Rio de Janeiro, 2003.

FARIA, M.G.G. A inclusão da Comunidade Santa Clara na sociedade da informação. 2011. Dissertação (Mestrado em Ciência da Informação) - Universidade Federal da Paraíba, João Pessoa, 2011.

FREIRE, G.H.A. A construção de instrumento para comunicação de informação sobre saúde. 1998. Dissertação (Mestrado em
O Laboratório de Tecnologias Intelectuais representa, também, uma oportunidade e um espaço de trabalho para os pesquisadores tecerem, no tear da Ciência da Informação, um padrão que (re)una informação, comunicação e computação, integrando pesquisa, ensino e extensão na práxis acadêmica.

Ciência da Informação) - Universidade Federal do Rio de Janeiro, Rio de Janeiro, 1998.

FREIRE, G.H.A. Comunicação da informação em redes virtuais de aprendizagem. 2004. Tese (Doutorado em Ciência da Informação) - Universidade Federal do Rio de Janeiro, Rio de Janeiro, 2004.

FREIRE, I.M. A responsabilidade social da Ciência da Informação e/ou O olhar da consciência possivel sobre o campo científico. 2001. Tese (Doutorado em Ciência da Informação) - Universidade Federal do Rio de Janeiro, Rio de Janeiro, 2001.

FREIRE, I.M. Acesso à informação e identidade cultural: entre o global e o local. Ciência da Informação, v.35, n.2, p.58-67, 2006.

FREIRE, I.M. Janelas da cultura local: abrindo oportunidades para inclusão digital. Rio de Janeiro: IBICT, 2009. (Relatório Final).

FREIRE, I.M. Projeto laboratório de tecnologias intelectuais - LTi. João Pessoa: UFPB, 2010. (Notas de trabalho).

FREIRE, I.M.; ALVES, E.C. Relatório do projeto oficina de criatividade científica. João Pessoa: UFPB, 2009.

FREIRE, I.M.; ALVES, E.C. Relatório do projeto oficina de criatividade científica. João Pessoa: UFPB, 2010.

GONZÁLEZ DE GÓMEZ, M.N. A globalização e os novos espaços da informação. Informare, v.3, n.1/2, p.72-97, 1997.

GONZÁLEZ DE GÓMEZ, M.N. O caráter seletivo das ações de informação. Informare, v.5, n.2, p.7-30, 1999a.

GONZÁLEZ DE GÓMEZ, M.N. Da política de informação ao papel da informação na política contemporânea. Revista Internacional de Estudos Políticos, v.1, n.1, p.57-93, 1999b.

GONZÁLEZ DE GÓMEZ, M.N. Novos cenários políticos para a informação. Ciência da Informação, v.31, n.1, p.27-40, 2002.

GONZÁLEZ DE GÓMEZ, M.N. Escopo e abrangência da ciência da informação e a pós-graduação na área: anotações para uma reflexão. Transinformação, v.15, n.1, p.31-43, 2003a.

GONZÁLEZ DE GÓMEZ, M.N. As relações entre ciência, Estado e sociedade: um domínio de visibilidade para as questões da informação. Ciência da Informação, v.32, n.1, p.60-76, 2003b.

GONZÁLEZ DE GÓMEZ, M.N. Novas fronteiras tecnológicas das ações de informação: questões e abordagens. Ciência da Informação, v.33, n.1, p.55-67, 2004.

HATSCHBACH,M.H.L. Information literacy: aspectos conceituais e iniciativas em ambiente digital para o estudante de nível 
superior. 2002. Dissertação (Mestrado em Ciência da Informação) - Universidade Federal do Rio de Janeiro, Rio de Janeiro, 2002.

KUHLTHAU, C. Inside the search process: information seeking from the user's perspective. Journal of the American Society for Information Science, v.42, n.5, p.362-375, 1991.

LÉVY, P. As tecnologias da inteligência: o futuro do pensamento na era da informática. Rio de Janeiro: Editora 34, 1994.

LÉVY, P. A inteligência coletiva: por uma antropologia do ciberespaço. 3.ed. São Paulo: Loyola, 2000.

LÉVY, P. A conexão planetária. Rio de Janeiro: Editora 34, 2001.

LÜCK, H. Metodologia de projetos: uma ferramenta de planejamento e gestão. 2.ed. Petrópolis: Vozes, 2003.

NOVELLINO, M.S.F. A transferência da informação através dos seus contextos de produção e uso: linguagens de transferência da informação. 2000. Dissertação (Mestrado em Ciência Informação) - Escola de Comunicação, Universidade Federal do Rio de Janeiro, Rio de Janeiro, 2000.

SARACEVIC, T. Ciência da Informação: origem, evolução e relações. Perspectivas em Ciência da Informação, v.1, n.1, p.41-62, 1996.

THIOLLENT, M. Pesquisa-ação nas organizações. São Paulo: Atlas, 1997.

THIOLLENT, M. Metodologia da pesquisa-ação. 10.ed. São Paulo: Cortez, 2000.

UNIVERSIDADE Federal do Paraná. Departamento de Ciência da Informação e Gestão da Informação. Gestão da informação. Curitiba: Universidade Federal do Paraná, 2002. Disponível em: <www.decigi.ufpr.br/>. Acesso em: 4 out. 2004.

WERSIG, G.; NEVELING, U. The phenomena of interest to information science. The Information Scientist, v.9, n.4, p.127-140, 1975. 